\title{
REFLEXÕES ONTOLÓGICAS DA PAISAGEM
}

\author{
ONTOLOGICAL REFLECTIONS OF THE LANDSCAPE \\ RÉFLEXIONS ONTOLOGIQUES DE LA PAYSAGE
}

\section{Raquel Fulino}

Mestranda pelo Programa de Pós-Graduação em Geografia da Universidade Estadual Paulista (UNESP - Campus Rio Claro). Bolsista FAPESP. Universidade Estadual Paulista "Júlio de Mesquita Filho", Instituto de Geociências e Ciências Exatas, Programa de Pós-Graduação em Geografia. Av. 24-A, no 1515 - CEP: 13506-900 - Rio Claro, SP. e-mail: rfulino@yahoo.com.br

\section{José Gilberto de Souza}

Pós-Doutorado na Universidad de Salamanca (Espanha). Professor Adjunto do Departamento de Geografia e do Programa de Pós-Graduação em Geografia da Universidade Estadual Paulista (UNESP - Campus Rio Claro). Pesquisador CNPq - Nível 2/FAPESP. Universidade Estadual Paulista "Júlio de Mesquita Filho", Instituto de Geociências e Ciências Exatas, Programa de Pós-Graduação em Geografia. Av. 24-A, no 1515 - CEP: 13506-900 - Rio Claro, SP. e-mail: jgilbert@rc.unesp.br

\section{Resumo}

A partir de uma breve análise da trajetória da categoria paisagem no âmbito do pensamento geográfico, o presente artigo objetiva desenvolver determinadas reflexões sobre o engendramento concreto da paisagem e a ontologia materialista e dialética. A legitimidade dessa discussão torna-se manifesta, especialmente, ao se vislumbrar quão imprescindível é o enfrentamento histórico-ontológico da paisagem em relação às abordagens metodológicas e ideológicas que encerram suas leituras geográficas na fragmentação/dicotomização dos elementos pertencentes à totalidade do real, unidade tão estimada ao pensamento marxista. Nesta direção, constata-se que as concepções de paisagem tem, historicamente, consolidado estas dicotomias, principalmente ao ser concebida enquanto externalidade do essencial, enquanto "falsa consciência" que dissimula a compreensão do concreto, condizente, assim, a um estatuto ontologicamente inferior à "essência" geográfica que representa. Contrariamente, busca-se desmistificar estas abordagens, revelando, por sua vez, a essencialidade da paisagem, ou seja, compreendendo-a enquanto fenômeno material e ontológico.

Palavras-chave: paisagem; ontologia; pensamento geográfico. 


\begin{abstract}
This article aims to develop specific reflections about the concrete articulation of the landscape and the materialistic and dialetical ontology. The legitimacy of this discussion becomes manifest especially when the geographers note how essential is the historical-ontological facing the landscape in relation to the methodological and ideological approaches to end their geographical readings fragmentation/duality of the elements belonging to the totality of reality, fundamental unity to Marxist thought. In this direction, it appears that the landscape concepts have historically consolidated these dualities, mainly to be designed as externality essential as "false consciousness" that hides the understanding of concrete. In contrast, the article seeks to demystify these approaches, revealing the essentiality of the landscape, that is, understanding it as a phenomenon materials and ontological.
\end{abstract}

Key-words: landscape; ontology, Geographical thought.

\title{
Résumé
}

A partir d'une brève analyse de la catégorie de paysage du chemin au sein de la pensée géographique, cet article vise à développer certaines réflexions sur le béton engendrant le paysage et l'ontologie et de la dialectique matérialiste. La légitimité de cette discussion se manifeste surtout quand imaginer comment essentiel est la méthode historicoontologique face au paysage par rapport aux approches méthodologiques et idéologiques pour mettre fin à leurs lectures géographiques fragmentation / dichotomie des éléments appartenant à la totalité de la réalité, l'unité comme estimé à la pensée marxiste. Dans ce sens, il semble que les concepts de paysage ont historiquement consolidé ces dichotomies, principalement pour être conçue comme externalité essentielle comme «fausse conscience» qui cache la compréhension du béton, conforme donc un statut ontologiquement inférieur à «essence» représentant géographique. En revanche, cherche à démystifier ces approches, révélant, à son tour, l'essentialité du paysage, qui est, la comprendre en tant que matériaux de phénomène et ontologique.

Mots-clés: paysage, l’ontologie, la pensée géographique. 


\section{INTRODUÇÃO}

Empreender uma discussão histórico-ontológica da categoria paisagem na Geografia brasileira no século XXI alude, de imediato, a um determinado "acerto de contas" ou, no melhor dos propósitos, aponta um novo horizonte teórico-metodológico a ser levantado pelas abordagens críticas, principalmente em função de leituras fragmentadas e unívocas sobre a paisagem, geradas no cerne do debate metodológico, gnosiológico e ideológico do movimento de renovação crítico-radical na década de 1970 (SOUZA, J. G., 2009a).

Leituras fragmentadas, unívocas e dicotômicas, que suscitaram, muitas vezes, no próprio abandono do emprego desta categoria em detrimento de outras - como espaço, território e até região - para a análise e interpretação das contradições sociais erigidas pela lógica capitalista de reprodução da existência humana. Resultado de um discurso empobrecido e envaidecido do marxismo vulgar, que lançara a paisagem a uma condição de inferioridade em relação ao concreto que representa e $e^{1}$, ou seja, a paisagem foi tomada como "estatuto ontologicamente secundário" (LESSA, 2007, p. 92) no interior de dada processualidade geográfica.

A paisagem tornara-se, nesse contexto, categoria destituída de mediações concretas, a qual mecanicamente incidia uma imagem invertida do real, uma vez que seu caráter fenomênico, seus atributos acidentais ${ }^{2}$ de aparência, só tinham sentido de ser para obscurecer as relações sociais (essenciais) da produção do espaço. Travavam-se, assim, de abordagens dualistas (não-dialéticas) do discurso geográfico: em um extremo, as determinações essenciais a-históricas, "primárias, transcendentais e primordiais" da realidade; e, em outro polo, a paisagem, que apontava um discurso geográfico imediatista, ou seja, sem trânsito entre a aparência e o seu próprio âmago (essência) (MOREIRA, 1987, p. 23).

Neste sentido, a proposta central deste texto é retomar aspectos específicos da trajetória da categoria paisagem na Geografia, porém assegurando os limites que esta tarefa, já de início, demarca: o ponto de partida não seguirá uma linear periodização recortada na história da ciência geográfica, a qual objetiva estabelecer a trama epistemológica que permitiu as transformações e ramificações do conceito de paisagem, tendo em vista sua "elasticidade conceitual na geografia" (VITTE, 2007), evidenciando o propósito desmedidamente amplo e complexo das diversas correntes, escolas e autores que trataram desta questão.

\footnotetext{
A paisagem não é pertencente a uma condição radicalmente diversa do concreto geográfico que manifesta, porém isto não permite afirmar que a mesma estabelece uma identidade ou uma dimensão refletora dos nexos internos, ou das propriedades estruturais, da essência.

2 Segundo Lalande (1999), acidental é tudo "aquilo que pertence ao acidente, não à essência", e "que acontece de uma maneira contingente ou fortuita".
} 
Assim sendo, os primeiros passos do texto buscarão uma desconstrução teórico-reflexiva de determinadas conceituações de paisagem, evidenciando, sobremaneira, como as dicotomias são centralidades nestas acepções. Para isto, a condução da análise está amparada sob duas bases: um eixo que assume a categoria em sua dimensão objetiva (em-si), enquanto conceito e objeto de estudo da (e na) ciência geográfica, designando, em verdade, espaço ou território; e o outro, que exprime a paisagem na acepção subjetiva, enquanto categoria que caracteriza, inclusive, uma dada "personalidade" terrestre, presumindo elementos estéticos de representação e aparência do real.

Presume-se, nesta direção, que as reflexões desenvolvidas permitirão estabelecer um quadro conceitual capaz de evidenciar as concepções de paisagem nas escolas do pensamento geográfico, engendrando, assim, os suportes centrais da proposta do texto, cujo escopo consiste em resgatar a dialeticidade ontológica na relação essência-fenômeno existente nesta categoria. E mais do que isso.

Embora as leituras dicotômicas na Geografia, inclusive determinadas abordagens marxistas, tenham, historicamente, mantido a paisagem como elemento extrínseco ao real, apregoando-a sinonimamente à noção ideológica enganadora de "falsa consciência", acredita-se que resgatar as contribuições da ontologia marxiano-lukácsiana nesta reflexão possibilitará refutar a paisagem de sua condição de externalidade, revelando o que a categoria efetivamente é: a concretude do concreto, ou melhor, a paisagem concebida enquanto fenômeno material e ontológico.

\section{ENTRE 0 QUADRO E LOCUS: LEITURAS DICOTÔMICAS DA PAISAGEM}

Não é preciso recorrer às reminiscências da noção de paisagem, que seguramente reportam à Antiguidade (MAXIMIANO, 2004), para compreender, em um primeiro momento, a clara fusão entre os elementos naturais e a experiência contemplativa (paisagística) do homem. Conformada a uma "fruição estética da natureza", como sugere Besse (2006), a busca do ser humano, seja na observação dos astros e constelações ou mesmo na apreciação de jardins suspensos, consistia, antes de tudo, nas tentativas de harmonização e proteção frente a uma natureza hostil e indecifrável ao ser humano (MAXIMIANO, 2004; GOMES, 2001).

Recorre-se, entretanto, a outra experiência contemplativa como ponto de partida da discussão, posto que, “(...) como se fosse colocar o mundo à distância ou, mais exatamente, colocar-se à distância do espaço terrestre (...)" (BESSE, 2006, p. 35), é evidente, segun- 
do Schier (2003), que as pinturas clássicas renascentistas dos séculos XVI e XVII permitem esquadrinhar uma das vertentes históricas do conceito de paisagem na geografia ${ }^{3}$.

Uma interpelação estética, porém, tencionada pela própria transição paradigmática que este período histórico impõe, diferenciado, por sua vez, pela disjunção do homem (sujeito) e da natureza (objeto), sendo esta entendida como algo passível de ser apropriado e transformado, e não mais uma dimensão intangível do real (SCHIER, 2003).

Neste sentido, a terminologia italiana moderna de paesaggio se estrutura no plano pictórico, de caráter descritivo-realista, combinando noções de perspectiva, profundidade e extensão (POLLETE, 1999), o que designaria, em verdade, a retratação do horizonte geográfico que "se descortina num só olhar" ou "a paisagem como teatro do mundo" (BESSE, 2006).

$\mathrm{O}$ aspecto visual apreendido na representação da paisagem se aproxima, por sua vez, da concepção de cenário - ou, como defende Santos (2006, p. 67), um "palimpsesto", cuja "imagem imobiliza um passado já morto" - de modo a expandir, inclusive, no âmbito geográfico, as práticas ou o campo de estudo intrínseco aos conhecimentos geográficos: a cartografia.

Em outras palavras, a pintura renascentista demarca o início de um longo processo de apreensão, formalização e sistematização das diversas (e diferentes) porções do planeta (RUSSO, 2007), prescrevendo a paisagem como um "ato mimético de representação do ecúmeno", que, por conseguinte, revela "visual e imaginariamente a promoção da geografia como discurso específico, distinto da cosmografia, consagrado à descrição da Terra universal" (BESSE, 2006, p. 23). Não é à toa, neste sentido, que o famoso atlas holandês de Abraham Ortelius, Theatrum orbis terrarum ${ }^{4}$ (c. 1570), por exemplo, fora elaborado sob tais pressupostos, pois:

Eis aqui expresso em termos de paisagens uma maneira de conceber a realidade que explicita o que são, desde as origens, as práticas dos geógrafos. Esses não são exploradores, viajantes ordinários ou turistas que se contentam em percorrer um itinerário. Eles desejam passar da observação local a uma visão que não negligencie nenhuma parcela do espaço: o exame da paisagem na vertical o permite; em sua ausência, o pesquisador se volta ao substituto da paisagem, que constitui a carta (CLAVAL, 2011, p. 64).

\footnotetext{
3 A outra vertente será retomada posteriormente a partir da concepção medieval alemã Landschaft, que estabelece uma ruptura com a perspectiva estético-subjetiva da paisagem, abordada inicialmente. O salto cronológico, no entanto, deve-se a uma opção meramente recursiva do texto, mesmo porque, conforme já anunciado, o objetivo principal não advém de um resgate histórico-linear da categoria paisagem na Geografia, e sim apontar alguns aspectos de sua trajetória conceitual que subsidiarão o debate ontológico. 4 Do latim, "Teatro do globo terrestre".
} 
Nesta direção:

Podemos então talvez compreender o que une o mapa-múndi e a representação artística da paisagem e, além disto, dar uma significação a este gesto que consiste em representar a Terra como uma paisagem. Nestes dois casos é preciso, por assim dizer, retirar-se, desprender-se da Terra para percebê-la como um todo. Não é preciso pertencer ao lugar para vê-lo (BESSE, 2006, p. 35).

Assim, tanto a paesaggio italiana quanto a pintura holandesa correspondem, de acordo com Vitte (2007), a duas concepções metafísicas da realidade.

A primeira delas, a representação que articula a noção de extensão (CHAUÍ, 1999 apud VITTE, 2007), orientando a composição de cenário nas descrições pictóricas, deixa explícito seus fundamentos neoplatônicos, uma vez que é o "olho humano que incide luz às coisas materiais para fazê-las visíveis" e o "pintor (...) serve como medida para a representação do mundo" (VITTE, 2007, p. 73).

É necessário, todavia, ponderação para que este argumento não se confunda com um viés materialista do sujeito em sua relação cognoscível com o mundo, já não que há, nos postulados neoplatônicos, um processo de apreensão intelectiva do objeto (a parcela do espaço geográfico a ser pintada/cartografada) mediante procedimentos analíticos e mediações concretas de síntese que se efetivam na consciência do sujeito (NETTO, J. P., 2011), ou seja, "uma aproximação da consciência ao ser-em-si” (LESSA, 1999, p. 01), concebendo-lhe existência (para-si).

O que se verifica, porém, é o primado do homem (próprio do Humanismo renascentista) (ROSA, 2010), que, pautado em uma clarividência-espelho sobre as coisas materiais, confere um sentido fenomênico à objetividade, visto que não há ruptura com a dimensão sensível-idealista.

Isto também se torna manifesto na segunda concepção metafísica, já que são os princípios ópticos de Kepler, desenvolvidos na pintura holandesa com a "paisagem do mundo", que transformam o olho humano em mero instrumento e mecanismo visual, o qual percorre as porções do planeta sem qualquer interferência (espectador), de modo a deixar autônomos o espaço e o movimento (tempo) em relação ao ponto de vista a ser esboçado/mapeado (VITTE, 2007).

O princípio ativo da natureza em relação à inércia do olhar humano assume, em outros termos, que a cognoscibilidade das coisas do mundo independe do sujeito, o que tende a ser pouco razoável do ponto de vista da ontologia histórico-materialista, dado que a apreensão da essência das coisas é sempre uma construção humana, um processo absolutamente histórico e que jamais se apresenta de forma absoluta (LUKÁCS, 2010). 
A respeito disso, é preciso sublinhar, contudo, que as origens da noção de paisagem não suscitam somente um sentido pictórico ou representativo, que determinam "(...) apenas uma referência espacial ou um objeto de observação (...)” (SCHIER, 2003, p. 81).

Etimologicamente, a paisagem também exprime uma “(...) conotação que pode ser caracterizada como geopolítica, designando uma unidade territorial onde se desenvolve a vida de pequenas comunidades humanas” (VITTE, 2007, p. 72), a qual, por sua vez, veiculou no termo medieval alemão Landschaft “(...) uma região de dimensões médias, em cujo território desenvolviam-se pequenas unidades de ocupação humana” (MAXIMIANO, 2004, p. 85).

Assim, com este alcance étimo do conceito de paisagem, sabe-se que:

(...) Dans les langues germaniques, le réferent est le territoire, alors que dans les langues latines le mot paysage a deux sens possible: celui d'image artistique (au sens de genre paysage), et celui de létendue visible d'um territoire (DONADIEU; PERIGORD, 2007, p. 09).

Isto revela, em última instância, uma dimensão objetiva de existência, já que, de acordo com Besse (2007, p. 21), Landschaft é inicialmente um lugar limitado por vizinhanças ou por conjuntos de propriedades (humanas ou naturais), cuja descrição constitui "sua qualidade ou natureza própria”.

A paisagem, neste sentido, embora assentada no plano descritivo e fenomênico, adquire condição expressiva (não representativa), pois é reconhecida objetivamente, cumprindo, portanto, função ontológica em-si (a paisagem "é” efetivamente) e epistemológica, particularmente do objeto de estudo corográfico, já que, neste caso, "o aspecto das coisas é uma realidade geográfica" (BESSE, 2006, p. 67).

Em suma, estas duas vertentes originárias do conceito de paisagem no pensamento ocidental - as dimensões estético-subjetiva (quadro) e a realista-objetiva (locus) -, assemelham-se, de modo geral, àquilo que Carl Troll (1997) reitera estar no cerne da atualidade do conceito: a paisagem envolve tanto a arte como a ciência. No entanto, “(...) somente a geografia deu ao seu uso um valor científico, transformando-o em eixo de toda uma teoria de investigação" (TROLL, 1997, p. 02).

De acordo com Gaspar (2001, p. 86), G. Dematteis polarizou igualmente as duas grandes tendências fundamentais do conceito de paisagem na ciência geográfica, que, de certa forma, ainda são permanentes e recorrentes nas diversas abordagens:

A paisagem como símbolo, isto é, como conjunto de sinais a serem decodificados; 
A paisagem como modelo, isto é, como construção racional e explicativa da realidade externa.

Não se trata, obviamente, de uma sistematização reducionista dos desdobramentos dessa categoria na Geografia, pois é certo que "os intercâmbios entre a ciência e a arte, no concernente à paisagem, são muito mais frequentes e muito mais profundos do que geralmente supõe" (BESSE, 2006, p. 62), de modo a engendrarem determinadas variações, como, por exemplo, um viés culturalista ou um relativo grau de "psicologismo" para a primeira perspectiva, e um naturalismo ou uma orientação ecológica para a segunda tendência.

Ademais, pensar a paisagem na qualidade de "valor científico", ou como "eixo de uma teoria de investigação", sinaliza, irrevogavelmente, refletir a geografia como projeto moderno de ciência (VITTE, 2007), que remete, por fim, a outra polarização do conceito, ou melhor, o processo de institucionalização da Geografia no final do século XIX manifesta a "vocação sintética" da paisagem em traduzir uma "unidade epistemológica à pesquisa geográfica" $(\mathrm{CH}$ RISTOFOLETTI, 1982, p. 14), seja na leitura da paisagem natural ou da paisagem cultural.

Esta dicotomização revela, por assim dizer, a constante interação, ou as múltiplas conexões decorrentes entre os elementos físicos e os elementos humanos na superfície (epiderme) terrestre (BERTRAND, 1971), capazes de inscrever na paisagem a configuração própria - a fisionomia - de um determinado lugar ou território, de modo a tornar-se, "com o tempo, como uma medalha que tem impressa a efígie de um povo" (LA BLACHE, 1979 apud BESSE, 2006, p. 69), pois, enquanto projeto de ciência e desígnio de sociedade, a paisagem moderna passa a refletir mimeticamente, como um espelho, uma dada civilização (MONBEIG, 1940).

Genericamente, as duas matriciais teóricas do pensamento clássico que pensaram a paisagem como objeto e campo de estudo geográfico, e que influenciaram a geografia brasileira na primeira metade do século XX, a saber, a Escola Alemã, de herança naturalista humboldtiana, e a Escola francesa, vinculada às possibilidades culturais de cada região (MAXIMIANO, 2004), apontam, em verdade, uma concepção superficial da realidade geográfica, que, em strictu sensu, assinalam externalidade e aparência fenomênica, já que "ambas tratam a paisagem como uma face material do mundo, onde se imprimiam as atividades humanas" (SCHIER, 2003, p. 80, grifo nosso).

Contudo, o que é efetivamente possível exprimir sobre essa questão da externalidade do conceito de paisagem (ou do objeto de estudo) no pensamento clássico diz respeito, de certa forma, às propriedades da categoria concebidas nos três níveis de conhecimento (CHEPTULIN, 1982). 
Baseando-se em Sposito (2001), tem-se que, no nível gnosiológico, a problemática da objetividade é entendida como um processo cognitivo inteiramente centrado no objeto (raciocínio lógico-dedutivo), de maneira que a existência do dado imediato aspira uma completa escusa de elementos subjetivos, o que condicionam os pressupostos históricos a um enfoque meramente sincrônico e linear (historicismo). No nível epistemológico, por conseguinte, a relação causa-efeito é o ditame da explicação científica, porque fundamentada na causalidade dos fenômenos e na percepção empírica regulada principalmente pela observação e descrição sistêmica do meio. E, por fim, no nível ontológico, a natureza aponta-se como entidade dissociada do ser humano e com estatuto próprio, além de que "a concepção de realidade parte de uma visão fixista, funcional e pré-definida" (SPOSITO, 2001, p. 102).

Besse (2006) resume a seu modo:

O promeneur geógrafo é então aquele que olha, associa [síntese] e dissocia [análise] o que ele olha, numa espécie de exercício constante da percepção. É um saber que progressivamente se estabelece, uma arte de julgar a paisagem. Mas esta atividade de julgamento, atividade ao mesmo tempo comparativa e discriminante, é antes de tudo uma atividade do olhar. Se o objeto é a paisagem, o sujeito deste julgamento é o olhar. O que vale dizer que uma reflexão sobre a geografia deve se articular a uma epistemologia dos saberes visuais, ou, mais exatamente, a uma indagação geral sobre o julgamento do olhar (BESSE, 2006, p. 74, grifo nosso).

Estas considerações, examinadas à luz da cautela, permitem reconhecer uma série de elementos do pensamento ocidental moderno que, consoante a Latour (1994), revelam que a separação entre natureza e sociedade, entre objetividade e subjetividade, nada mais é do que um mecanismo ou um instrumento de isolar (purificar) uma realidade híbrida, na qual o conhecimento científico trata de ilibar em seu exercício.

É o que se aproxima do "purismo" da objetividade na Geografia clássica, ou melhor, o processo cognitivo inteiramente embasado no objeto de estudo, que renova "o interesse pelo mundo, ao testar o poder de observação e examinar até onde vão a ciência e os conhecimentos, se os olhos estão limpos e veem com clareza" (GOETHE, 1999, p. 30), de modo a explicitar, contraditoriamente, a relutância em consolidar um caminho epistêmico e metodológico apartado da dimensão estético-subjetiva.

Prerrogativa que se reafirma ao sentenciar uma natureza em-si (objeto), que tem como premissa a recusa do sujeito histórico como ser ontologicamente capaz de delegar sen- 
tido e existência às coisas materiais ${ }^{5}$ em detrimento de uma "atividade do olhar" (sujeito), reavivando, em certo grau, "a sublimidade do Eu fichteano", característico da estética romântica germânica dos séculos XVIII e XIX'.

Uma leitura que traz à tona, assim, a "epistemologia dos saberes visuais" ou, como $a$ priori gostariam os geógrafos, a "ciência da paisagem", como uma tênue demarcação entre ciência e estética, entre objetividade e subjetividade, tendo em vista que "a flutuação da doxa é substituída pela episteme (...), e posteriormente constituída como ciência geográfica” (BARBOSA, NUNES, 2011, p. 188).

A paisagem, portanto, encontra centralidade na ordem da representação, no campo de uma dada externalidade que, ao mesmo tempo em que evoca um encaminhamento sintético às abordagens e investigações geográficas, engendra, por outro lado, profundos fracionamentos na compreensão das determinações concretas dos espaços e das espacialidades, pois se constitui, verdadeiramente, em uma articulação sistêmica, porém estagnada (não dialética), entre os "elementos naturais" (a hidrografia, o relevo, as formações fitogeográficas, etc.), e os "elementos humanos" (as construções, redes de transportes, etc.) sobre (ou dentro de) uma base geográfica a-histórica, porque não é processual, e quase incognoscível, pois destituída de contradições.

Uma fragmentação conceitual que, embora simulada em outras definições e perspectivas teóricas, estas, contrariamente, ratificam a dimensão superficial da paisagem. É evidente que ainda que não seja reduzida, em muitos casos, a uma forma terrestre que se respalda meramente em sua peculiaridade física, a compreensão de paisagem, nestes termos, não se desvencilha, todavia, do caráter fisionômico, também fundada na concepção dualista entre aspectos físicos e humanos, como destaca Sauer (1925), por exemplo, representante da geografia cultural clássica:

Paisagem é o equivalente inglês para o termo que os geógrafos alemães estão usando amplamente, e tem estritamente o mesmo significado: uma forma da Terra na qual o processo de modelagem não é de modo algum imaginado como simplesmente físico. Ela pode ser, portanto, definida como uma área composta por uma associação distinta de formas, ao mesmo tempo físicas e culturais (SAUER, 1925, p. 23).

\footnotetext{
5 Não se trata, entretanto, de refutar irracionalmente a coisa em-si, denominada, na concepção marxiano-lukácsiano, "objetividade primária". Isto porque "um ente não se altera pelo fato de ser ou não conhecido pelos homens. Contudo, (...) certamente modifica-se - por vezes radicalmente - a relação dos homens com esse setor da realidade" (LESSA, 1999, p. 02). Em outros termos, "o real existe, tem uma natureza e esta existência e esta natureza são capturáveis intelectualmente e podem ser modificadas pela ação cientificamente instruída, ideológica e conscientemente conduzida pelo homem” (VAISMAN, 1989, p. 40).

6 Para aprofundar esta discussão, tem-se como referência: SILVEIRA, R. W. D., Filosofia, arte e ciência: a paisagem na Geografia de Alexander Von Humboldt. Campinas, 2012 (Tese de Doutoramento); MATTOS, C. V., A pintura de paisagem entre arte e ciência: Goethe, Hackert e Humboldt. Revista Terceira Imagem. Univ. Federal do Rio de Janeiro, Centro de Letras e Artes, Faculdade de Letras, Ano IX, n. 10, 2004, pp. 152-170.
} 
Em contrapartida à Escola de Berkeley do americano Sauer, que privilegiou a abordagem morfológica da paisagem até à década de 1940, verifica-se, por sua vez, a retomada dos enfoques subjetivos da paisagem a partir da década de 1970 (CORRÊA, 1997), porém com outras acepções.

De maneira geral, é razoável distinguir o hiato e a não predominância dos estudos da paisagem durante as décadas de 1950 e 1960, que foram alavancados nas décadas seguintes com um viés fortemente subjetivo, principalmente com os estudos da Nova Geografia Cultural, cujas abordagens envolvem, por exemplo, as pesquisas fenomenológicas, existencialistas, entre outras (CORRÊA, 1995, p. 50).

Abordagens teórico-metodológicas que, em seu bojo, provocaram debates e enfretamentos ao positivismo lógico (neopositivismo) e ao movimento de renovação teorético-quantitativa da ciência geográfica, o qual, "englobando processos de abstração necessários às etapas da metodologia científica e da explicação" (CHRISTOFOLETTI, 1982, p. 17), referendavam uma ciência objetiva, matematizada e, sobretudo, pretensamente neutra.

Portanto, é legítimo apontar, inclusive, algumas tentativas da Nova Geografia Cultural de redirecionamento na compreensão da paisagem no sentido de externalidade, emergindo transformações do conceito que acentuam "a paisagem [como] sinônimo de ausência de objetivação, [visto que] ela precede a distinção entre sujeito e objeto, e a aparição da estrutura do objeto" (BESSE, 2006, p. 79). Tentativas - embora debalde - de redirecionar a dimensão fisionômica da realidade geográfica ao terreno dos enfoques “internalistas", mesmo reconhecendo ainda uma trajetória epistêmica densamente situada no plano fenomênico e representativo.

Isto quer dizer que a paisagem tornara-se categoria prenhe de acepções e significados a serem descobertos pelo homem em sua relação com mundo, de modo a desvendar, assim sendo, "a natureza dessa terrae incognitae e a relação entre o mundo exterior e as imagens em nossa cabeça" (LOWENTHAL, 1976, p. 104).

Tratam-se, certamente, de abordagens teórico-metodológicas que revelaram, no âmago, suas debilidades na exarcebação do indivíduo, ao sustentarem dimensões indutivas e particularizadoras, desprovidas de processualidade histórica e materialidade, de modo a perderem-se, muitas vezes, em tautologias subjetivistas; o que não desconsidera, todavia, o salto qualitativo em relação às orientações positivistas e neopositivistas.

Por outro lado, "tomada pelo indivíduo, a paisagem é forma e aparência. Seu verdadeiro conteúdo só se revela por meio das funções sociais que lhe são constantemente atribuídas no desenrolar da história” (LUCHIARI, 2001, p. 13), o que convida o geógrafo a: 
(...) resistir à tentação de deslocar a paisagem de seu contexto de tempo e espaço, enquanto estivermos cultivando nossa capacidade imaginativa de incorporá-la para vê-la, por assim dizer, por dentro. Finalmente, em tal geografia, a linguagem é crucial. Os resultados de nosso estudo são comunicados primeiramente através dos textos que nós mesmos produzimos. O texto de uma interpretação geográfica da paisagem é o meio através do qual transmitimos seu significado simbólico, através dos quais re-presentamos esses significados (...) (COSGROVE, 2004, pp. 110-111).

A tradução - como uma linguagem textual - do "verdadeiro conteúdo" da paisagem, assim sendo, não é determinada por si só, mas "por meio das funções sociais que lhe são atribuídas historicamente", consolidando-se, no limite, enquanto "testemunho humano" (BESSE, 2006).

Isto torna claro que, no final dos anos 1980, a linha teórica de Denis Cosgrove, James Duncan, entre outros geógrafos da Nova Geografia Cultural, propõe “a integração entre o materialismo dialético e os aspectos subjetivos na apreensão da paisagem” (MELO, 2001, p. 31), de maneira a expandir um campo investigativo empenhado em desatar o imbróglio referente à cisão dos elementos opostos da realidade geográfica.

Uma preocupação, há de se rever, diminutamente levantada pela perspectiva marxista, a qual não deixou de rejeitar, inclusive, o próprio emprego do conceito de paisagem em suas pesquisas, evidenciando, nesse descompasso, a não consolidação de análises fundamentalmente críticas, ou seja, que trouxessem da raiz as funções e determinações concretas da referida categoria no âmbito da Geografia.

Análises críticas que significam, em outras palavras, realizar um caminho reflexivo que supere a problemática da paisagem nos termos gnosiológicos e epistemológicos; primeiro, porque, como já visto nos parágrafos anteriores, esta direção já conta com ampla bibliografia, e segundo porque, tanto para Marx quanto para Lukács, o problema fundante do objeto (ou, no caso, das categorias e conceitos) não se resume a uma propositura metodológica (LESSA, 1999, p. 04), que parta, abstratamente, do objeto de estudo em si, e sim uma reflexão metodológica que "sature o objeto pensado em suas determinações mais concretas" (NETTO, 2011, p. 53), isto é, uma reflexão materialista e ontológica.

\section{DA ONTOLOGIA DA PAISAGEM À UNIDADE DOS OPOSTOS: UM EXERCÍCIO METODOLÓGICO}

Se, em uma direção, as reflexões da ontologia histórico-materialista ${ }^{7}$ da paisagem almejam responder, de certo modo, as disjunções positivistas de um marxismo vulgar no conhecimento geográfico, em outro viés, estabelecem igualmente determinados embates aos paradigmas da acumulação flexível e do pensamento pós-moderno decorrentes das últimas décadas do século XX.

a 7 Oportunamente distinguida das ontologias idealistas que operam dos gregos a Hegel na história da filosofia ocidental (LESSA, 2007). 
Tem-se que tais paradigmas ensejam determinados matizes de suas concepções na categoria paisagem, como evidenciados pela fluidez imagética dos processos de apreensão do visível, ou seja, a velocidade e a fragmentação espaço-temporal em dimensões absolutamente "fotográficas", momentâneas (HARVEY, 1993), que são incapazes de apreender o movimento concreto das espacialidades, das territorialidades, e também de suas representações.

As concepções pós-modernas, neste sentido, "dissimulam o conceito, proíbem a reflexão, impedem sua formação e até a consciência de sua necessidade" (MARACCI; SOUSA, 1995, p. 41), principalmente ao exaltarem a criação de pseudocategorias explicativas do real, cujas designações conceituais apelam, muitas vezes, a interpretações relativistas (individualizadas), de modo a propalar as análises históricas a uma condição político-ideológica antiquada na esfera científica.

Por outro lado:

Percebe-se que as categorias e conceitos não são abstratos, não se estabelecem a priori, mas são produtos das relações, engendrados por elas e grávidos de historicidade, de acordo com os diversos níveis das relações humanas, das condições materiais que os engendram. Isso revela seu caráter ontológico, representações humanas de condições humanas de vida, mediadas por relações sociais, de produção e reprodução material e imaterial dos homens (SOUZA, J. G., 2009a, n/p).

Neste sentido, embora a categoria paisagem esteja centrada na ordem fenomênica, na aparência visível dos aspectos geográficos, tergiversando, ora mais ora menos o quadro e o locus, é fundamental compreender, por sua vez, que a paisagem é essencialmente um constructo humano, que não se consolida autonomamente no intelecto dos sujeitos, ao contrário dos argumentos que a reiteram como fruição espiritual que vagueia a epiderme do mundo.

Assim:

(...) O objetivo do pesquisador, indo além da aparência fenomênica, imediata e empírica (...) é apreender a essência (...) do objeto. (...) Alcançando a essência do objeto, (...) por meio de procedimentos analíticos e operando a sua síntese, o pesquisador a reproduz no plano do pensamento; mediante a pesquisa, viabilizada pelo método, o pesquisador reproduz, no plano ideal, a essência do objeto que investigou (NETTO, J. P., 2011, p. 22).

A distinção e o entendimento da complexidade de relações entre aparência e essência, bem como as formas ou modos de apreensão da realidade pelo ser humano, revelam-se, por assim dizer, centrais no pensamento ontológico de Marx, dado que toda processualidade histórica se desenvolve, inexorável e obrigatoriamente, conforme um duplo-momento dialeticamente engendrado do ser (LESSA, 2002): 
O desdobramento categorial do ser dá origem a dois momentos distintos, porém intrinsecamente articulados. Um primeiro momento é composto por aqueles elementos que articulam em unidade o processo enquanto tal. Tais elementos marcam a continuidade do processo no interior de seu devir, são a sua essência. O segundo momento é dado por aqueles elementos que distinguem cada instante de todos os outros instantes. Essa esfera fenomênica, todavia, apenas pode vir a ser articulada aos momentos de continuidade, que fazem dessas características fenomênicas partícipes de um dado processo mais geral (LESSA, 2002, p. 57).

Estas reflexões já explicitam que "o processo de aproximação da consciência ao real diz respeito tanto às dimensões universais quanto às particulares dos objetos envolvidos" (LESSA, 1999, p. 02), de maneira que as operações intelectivas de análise e síntese do sujeito em relação ao objeto geográfico, e a sua compreensão, não dualizam, como uma "purificação", os elementos fenomênicos dos elementos essenciais.

Neste sentido, a paisagem efetivamente apresenta uma concretude e cumpre determinações ontológicas específicas no interior de uma processualidade geográfica, ou seja, exerce uma influência real (quantum) no desdobramento dos elementos essenciais.

Trata-se de desmitificar outra postulação equivocada, e comumente aceita, de que a realidade é o mesmo que essência. Precipitada afirmação que delega à aparência um caráter meramente "enganador" e dispensável. A realidade abrange o conceito e a representação, o movimento real interno e o movimento visível, a lei dos fenômenos e a aparência externa dos fenômenos, a consciência real e a falsa consciência (NETTO, J. P., 2011), pois "o fenômeno indica a essência (...). A manifestação da essência é precisamente a atividade do fenômeno" (KOSIK, 1976, p. 11), caso contrário, se tais tangências e mediações concretas não existissem, a compreensão da essência do objeto adquiriria um viés ontológico idealista.

(...) A abstração é a capacidade intelectiva que permite extrair de sua contextualidade determinada (de uma totalidade) um elemento [objeto], isolá-lo, examiná-lo (...). A abstração, possibilitando a análise, retira do elemento abstraído as suas determinações mais concretas, até atingir "determinações as mais simples". Neste nível, o elemento abstraído torna-se "abstrato" - precisamente o que não é totalidade de que foi extraído: nela, ele se concretiza porquanto está saturado de "muitas determinações". A realidade é concreta exatamente por isso, por ser a "síntese de muitas determinações", "a unidade do diverso" que é a própria de toda totalidade. O conhecimento teórico é, nesta medida, para Marx, o conhecimento do concreto, (...) mas não se oferece imediatamente ao pensamento: deve ser reproduzido por este e só "a viagem de modo inverso" permite esta reprodução (NETTO, J. P.; 2011, p. 44). 
Nas palavras de Kosik (1976), esta "viagem de modo inverso" define-se propriamente como détour ou desvio: o caminho sistêmico da formação material, a materialidade concreta, para a abstração e vice-versa. Por sua vez, vislumbra-se o "movimento da parte para o todo e do todo para a parte; do fenômeno para a essência e da essência para o fenômeno; da totalidade para a contradição e da contradição para a totalidade; do objeto para o sujeito e do sujeito para o objeto" (KOSIK, 1976, p. 30), cujo desígnio consiste em se romper a pseudoconcreticidade (KOSIK, 1976) das coisas do mundo.

A ruptura da pseudoconcreticidade, por conseguinte, permite a compreensão de que “(...) categorias e conceitos de análise não se reduzem a uma forma taxonômica, mas teórico-prática (...)" (SOUZA, J. G., 2009a, n/p), e que "a problemática fundante do objeto de estudo", que articule uma reflexão metodológica que "sature o objeto pensado em suas determinações mais concretas", significa desnudar a estrutura, a dinâmica e as determinações deste objeto de análise. Este processo intelectivo possibilita o engendramento da produção teórica do conhecimento "sobre a materialidade da natureza humana, em sua essencialidade: o trabalho" (SOUZA, J. G., 2009a: n/p), de modo a desvencilhar-se, finalmente, do caráter neutro e natural do fazer científico, do fazer geográfico.

Portanto, quais são os aspectos decisivos a serem encaminhados e constantemente refletidos pelo geógrafo frente a um debate da ontologia histórico-materialista da paisagem? Talvez Besse (2006) proponha um caminho:

O ponto de partida da análise geográfica seria, sem dúvida, o seguinte: mesmo sendo a paisagem uma dimensão do visível, esta paisagem é o resultado, (...) ainda que indireto e complexo, de uma produção. A paisagem é um produto objetivo, do qual a percepção humana só capta, de início, o aspecto exterior. (...) Ao mesmo tempo, a intenção e a esperança científicas do geógrafo consistem em tentar ultrapassar esta superfície, esta exterioridade, para captar a "verdade" da paisagem (BESSE, 2006, p. 65).

A paisagem, portanto, ao comportar um estatuto inerente à esfera fenomênica, da ordem representativa e aparente, se traduz, de modo singular, em "um claro-escuro de verdade e engano" (KOSIK, 1976, p. 11), a qual, intrinsecamente, traz-afasta a essência. Seja a paisagem enquanto "fruição estética da natureza", seja enquanto representação cartográfica que pormenoriza e descreve os elementos geográficos do mundo, seja também a paisagem como "dimensão objetiva de existência”, consoante ao seu caráter de externalidade; o que é preciso elementarmente ser considerado é o entendimento da dialeticidade ontológica e material proposta por esta categoria de análise.

Neste caminho, é admissível apoiar-se, em certa medida, nas contribuições geradas na obra A Imaginação (1973), em que Sartre tece uma sólida argumentação, certamente 
voltada aos estudos do campo da psicologia e alguns questionamentos nesta área, mas que admite alguns eixos reflexivos que sustentam a presente problemática.

Analisa-se, inicialmente, como a existência das coisas se apresenta na realidade: a simples presença e inércia de uma folha posta sobre a mesa, exemplo que o autor sugere, independentemente de qualquer consciência, existe "em si" (isto sem levar em consideração todo processo de trabalho humano pelo qual a folha foi gerada), ou seja, reconhece-se a "objetividade primária” do objeto.

Por outro lado, e ao mesmo tempo, as apreensões de sua forma, cor e posição pela consciência, sob a constatação e o julgamento do sujeito, tornam-na um ser "para si”. Caso o olhar humano não mais se dirija a ela, conservando-a, porém, ainda "viva" na mente, a folha posta sobre a mesa deixará de ser "para si”, não sendo, por sua vez, aniquilada - ainda existe "em si" -, porém agora ela existe de outra forma:

(...) É bem a mesma folha, a folha que está presentemente sobre minha escrivaninha, mas existe de um outro modo. Eu não a vejo, ela não se impõe como um limite à minha espontaneidade; (...). Em uma palavra, ela não existe de fato, existe em imagem (SARTRE, 1973, p. 41, grifo nosso).

Nas páginas seguintes de sua obra, Sartre adverte que a confusão gerada entre os grandes metafísicos dos séculos XVII e XVIII - Descartes, Leibniz, Hume -, foi a de terem elaborado uma teoria da imagem (imaginação) a priori, ou seja, misturaram indevidamente essência e existência, o que denominou como uma "ontologia ingênua".

Era como se a imagem da coisa fosse a própria coisa que representava, não havendo mais possibilidades de distinção entre ambas. É como confundir uma pintura ao seu modelo; ora, é como aceitar, no âmbito geográfico, a afirmação de que os seres humanos projetam-se e criam suas condições de existência e reprodução na paisagem.

Em outras palavras, deve-se compreender que a paisagem se refere à concretude espaço-temporal que manifesta as dinâmicas dos espaços e territórios (SOUZA, J. G., 2008), mas que, simultaneamente, não se dissolve numa "identidade" com o real geográfico que evidencia, como ambicionaram os clássicos.

Apesar da "consciência e da objetividade [serem] processualidades históricas, [e que] a relação entre elas jamais se esgota, o movimento intrínseco a cada uma torna ontologicamente impossível qualquer identidade sujeito-objeto" (LESSA, 1999), ou qualquer identidade fenômeno-essência, apesar das correlações e aproximações que envolvem a unidade e a totalidade do ser. Portanto, a paisagem não é o concreto "em si", mas uma concretude do concreto (SOUZA, J. G., 2008: n/p). 
Cheptulin (1982) esclarece:

Como os materialistas pré-marxistas, também os fundadores do materialismo dialético consideravam que as categorias representam as imagens ideais que refletem os aspectos e os laços correspondentes das coisas materiais. Entretanto, à diferença dos materialistas pré-marxistas, que afirmam que o conteúdo dessas imagens coincide diretamente com as propriedades e os laços correspondentes das coisas, o marxismo considera que essas imagens são o resultado da atividade criadora do sujeito no decorrer da qual este último distingue o geral do singular. Esse geral exprime as propriedades e as correlações internas necessárias. É por isso que a imagem ideal que representa o conteúdo dessa ou daquela categoria, sendo a unidade do subjetivo e do objetivo, não coincide imediatamente com os fenômenos, com os quais se encontra na superfície das coisas. Pelo contrário, ela se distingue sensivelmente dos fenômenos e chega mesmo a contradizê-los, já que eles não coincidem com sua essência. O conteúdo das categorias deve coincidir e coincide até determinado ponto, não com o fenômeno, mas com sua essência, com esse ou aquele de seus aspectos (CHEPTULIN, 1982, p. 18, grifo nosso).

O movimento dialético estabelecido pela ontologia da paisagem é revelador não somente daquilo que está dado no real, mas também do sujeito que o outorga como fenômeno, explicitando uma articulação entre sujeito-objeto e seu contexto histórico, já que o sujeito criador da representação (paisagem) tem dimensões de atividades socio-históricas relativas aquele produto representado (SOUZA, J. G., 2008: n/d).

Portanto, a construção de categorias e conceitos não evidencia somente um modo de compreensão epistemológico (científico) do sujeito sobre um objeto da realidade, mas, simultaneamente, manifesta as determinações histórico-ontológicas e ideológicas do próprio sujeito, despindo-lhe, no limite, valores, interesses, visões de mundo (MORAES, 1988) em sua atividade científica, em sua praxis.

Por sua vez, a manifestação das determinações históricas do sujeito neste processo consolida o movimento da abstração, anteriormente apontado por Cheptulin (1982) - a unidade entre subjetividade-objetividade -, o que legitima, por conseguinte, a compreensão de que categorias e conceitos, a paisagem, especificamente, aufere suas dimensões materiais e ontológicas.

Nesta direção:

(...) a relação com a paisagem é principalmente animada por uma intenção de conhecimento e de intervenção, ou seja, de projeto, sobre o território. Note-se enfim que, nesta perspectiva, o conceito de paisagem não é unicamente uma vista, é antes um território ou um sítio. Mesmo que este sítio ou este território sejam visíveis, seu ser não se reduz à sua visibilidade. O problema que se coloca neste último caso é o de conseguir apreender a relação entre a dimensão visível da paisagem e aquela que não é (BESSE, 2006, p. 64). 
A paisagem indica a estrada, já que repousa na representação, na dimensão imediatamente visível e aparente do objeto, porém, somente o desprendimento de sua "pseudoconcreticidade", ou seja, a ruptura com "os jogos de prestidigitação do real” (MOREIRA, 1987, p. 157), revelará a essencialidade do constructo geográfico: a projeção concreta da ação humana em determinado tempo histórico - espaço geográfico - e a apropriação de tais espaços mediante relações de poder historicamente construídas, os territórios efetivamente (SOUZA, J. G., 2009b).

\section{CONSIDERAÇÕES FINAIS}

As reflexões ontológicas enredadas à categoria paisagem deram-se com intuito de reacendê-la, dentro das reais condições de um artigo, na pauta das interpretações e preocupações do materialismo histórico e dialético nas pesquisas e estudos geográficos, de modo a subtraí-la de certa "posição marginal" ou menos relevante em relação a outras categorias de análise.

Ao mesmo tempo, estas reflexões aspiram à ruptura com as abordagens que retalham a realidade em dimensões diametralmente opostas do real, que, sem compreenderem a dialeticidade existente na unidade do ser, negam uma parcela desse real, o qual revelou-se, contrariamente, de extrema relevância para a compreensão das determinações mais concretas e da dinâmica interna e fundante de dada processualidade.

No entanto, parafraseando Lefebvre (1975), o criador não pode permanecer nas aparências, ou melhor, o pesquisador não deve circunscrever a profundidade da análise geográfica unicamente na paisagem, tendo em vista que a criação (objeto para-si) ultrapassa as mediações e representações, porém sem destruí-las, mas assimilando-as e negando-as dialeticamente.

\section{REFERÊNCIAS}

1. BARBOSA, T.; NUNES, J. O. Kant, estética romântica germânica e Humboldt: percurso da Geografia. Revista Caminhos da Geografia, Uberlândia, v. 12, n. 38, jun/2011, pp. 187-199.

2. BERQUE, A. (dir). Cinq Propositions pour une théorie du paysage. Seyssel: Champ Vallon, 1994.

3. BERTRAND, G. Paisagem e geografia física global: um esboço metodológico. Revista IGEOG/ USP, São Paulo: USP, n. 13, 1971. Caderno de Ciências da Terra. 
4. BESSE, J. M. Ver a Terra. Seis Ensaios Sobre a Paisagem e a Geografia. Editora Perspectiva, 2006.

5. CHePtUlin, A. A Dialética Materialista. Categorias e leis da dialética. Trad.: Leda Rita Cintra Ferraz. São Paulo, Editora Alfa-Ômega, 1982.

6. CHRistofoletti, A (org.). Perspectivas da Geografia. São Paulo: Difel, 1982.

7. CLAVAL, P. Epistemologia da Geografia. Trad.: Margareth C. A. Pimenta; Joana A. Pimenta. Florianópolis: Ed. da UFSC, 2011.

8. CORRÊA, R. L. A paisagem geográfica - uma bibliografia. In: Revista Espaço e Cultura, n. 4, Rio de Janeiro: NEPEC/UERJ, 1997, pp. 50-54.

9. COSGROVE, D. A geografia está em toda a parte: cultura e simbolismo nas paisagens

10. humanas. In: CORREAA, R. L.; ROSENDAHL, Z. (Org.). Paisagem, Tempo e Cultura. Rio de Janeiro: EdUERJ, 2004.

11. DONADIEU, P.; PÉRIGORD, M. Le Paysage. Entre natures et cultures. Paris: Armand Colin, 2007.

12. GASPAR, J. O retorno da paisagem à Geografia: apontamentos místicos. Revista Finisterra, n. 35 , v. 72,2001 , pp. 83-99.

13. GOETHE, J. W. Viagem à Itália. São Paulo: Cia das Letras, 1999.

14. GOMES, E. T. A. Natureza e Cultura - representações na paisagem. In: ROSENDAHL, Zeny \& CORRÊA, Roberto Lobato (Org.). Paisagem, imaginário e espaço. Rio de Janeiro: EdUERJ, 2001.

15. HARVEY, D. Condição Pós-Moderna. São Paulo: Ed. Loyola, 1993.

16. KOSIK, K. Dialética do Concreto. Trad.: Célia Neves e Alderico Toríbio. 2 ed. Rio de Janeiro: Paz e Terra, 1976.

17. LALANDE, A., Vocabulário Técnico e Crítico da Filosofia. Trad.: F. S. Correia; M. E. V. Aguiar; J. E. Torres; M. G. Souza. São Paulo: Martins Fontes, 1999.

18. LATOUR, B. Jamais fomos modernos. Ensaio de antropologia simétrica. Trad.: Carlos Irineu da Costa. Rio de Janeiro: Ed. 34, 1994.

19. LEFEBVRE, H. Lógica formal, lógica dialética. Rio de Janeiro: Civilização Brasileira, 1975.

20. LESSA, S. Lukács, Ontologia e Método. Em busca de um(a) pesquisador(a) interessado(a). Revista Praia Vermelha, Rio de Janeiro, v. 1, n. 2, 1999.

21. LESSA, S. Mundo dos homens: trabalho e ser social. São Paulo: Boitempo Editorial, 2002.

22. LESSA, S. Para compreender a ontologia de Lukács. $3^{\text {a }}$ ed. Ijuí: Ed. Unijuí, 2007 (Coleção Filosofia).

23. LOWENTHAL, D. Geografia, experiência e imaginação: em direção a uma epistemologia geográfica. In: Perspectivas da geografia. São Paulo: Difel, 1976, pp. 103-140.

24. LUCHIARI, M. T. D. P., A (re)significação da paisagem no período contemporâneo. In: ROSENDAHL, Z.; CORREAA, R. L.(orgs.). Paisagem, imaginário e espaço. Rio de Janeiro: EdUERJ, 2001. 
25. LUKÁCS, G. Prolegômenos para uma ontologia do ser social. Questões de princípios para uma ontologia hoje tornada possível. Trad.: Lya Luft e Rodnei Nascimento. Superv.: Ester Vaisman. São Paulo: Boitempo, 2010.

26. LUKÁCS, G. Ontologia do Ser Social: Os Princípios Ontológicos Fundamentais de Marx. São Paulo: Ciências Humanas, 1979.

27. MARACCI, M. T.; SOUSA, S. A. Modernidade: algumas abordagens. Revista Formação, v. 1, n. 2, Presidente Prudente, 1995, pp. 36-51.

28. MAXIMIANO, L. A. Considerações sobre o conceito de paisagem. Revista RAEGA, Curitiba, n. 8, pp. 83-91, 2004.

29. MELO, V. M. Paisagem e simbolismo. In: ROSENDAHL, Z.; CORRÊA, R. L.(orgs.). Paisagem, imaginário e espaço. Rio de Janeiro: EdUERJ, 2001.

30. MONBEIG, P. A paisagem, espelho de uma civilização. Ensaios de Geografia Humana, Livraria Martins, 1940, pp. 109-117.

31. MORAES, A. C. R. Ideologias Geográficas. Espaço, Cultura e Política no Brasil. São Paulo: Editora Hucitec, 1988.

32. MOREIRA, R. O Discurso do Avesso. Para a crítica da geografia que se ensina. Rio de Janeiro: Dois Pontos, 1987.

33. NETTO, J. P. Introdução ao estudo de Marx. São Paulo: Editora Expressão Popular, 2011.

34. POLLETE, M. Paisagem: uma reflexão sobre um amplo conceito. Revista Turismo Visão e Ação, 1999.

35. ROSA, R. A. A sombra de Orfeu. O neoplatonismo renascentista e o nascimento da ópera. Porto Alegre: EDIPUCRS, 2010.

36. RUSSO, A. "Caminando sobre la tierra, de nuevo desconocida, toda cambiada". Revista Terra Brasilis [Online], 7-8-9, 2007. Disponível em: http://www.terrabrasilis.revues.org/388. Acessado em: junho de 2015.

37. SANTOS, M. A Natureza do Espaço. Técnica e Tempo, Razão e Emoção. 4 ed. São Paulo: EdUSP, 2006.

38. SARTRE, J. P. Conferências e escritos filosóficos: O existencialismo é um humanismo; A imaginação; Questão de método. São Paulo: Abril Cultural, 1973.

39. SAUER, Carl. Morfologia da Paisagem. Trad. Gabrielle Côrrea Braga. Revisão de

40. Roberto Lobato Corrêa, Departamento de Geografia, UFRJ. University of California:

41. Publications in Geography, vol. 2, no 2, 1925, pp. 19-54.

42. SCHIER, R. A. Trajetórias do conceito de paisagem na Geografia. RAEGA, Curitiba: Editora UFPR, n. 7, 2003, pp. 79-85.

43. SOUZA, J. G., Geografia e Método: elementos teóricos da pesquisa geográfica. In: Uma mirada sobre o rural Espanhol: a homogeneidade do território e da paisagem. Universidad de Salamanca/FAPESP. Salamanca, 2009 a, s/n. 
44. SOUZA, J. G. Limites do território. Revista Agrária, São Paulo, no 10/11, 2009 b. pp. 99-130.

45. SOUZA, J. G. Por uma ontologia da paisagem. Rio Claro/UNESP, 2008, n/p, (Projeto de Pesquisa).

46. SILVEIRA, R. W. D., Filosofia, arte e ciência: a paisagem na geografia de Alexander Von Humboldt. Campinas: IFCH, 2012 (Tese de Doutoramento).

47. SPOSITO, E. S. A propósito dos paradigmas de orientações teórico-metodológicas na Geografia contemporânea. Revista Terra Livre - AGB, São Paulo, n.16, 2001, pp. 99-113.

48. TROLL, C. A paisagem geográfica e sua investigação. Trad: Gabrielle Côrrea Braga. Revista Espaço e Cultura, n. 4, jun/1997, pp. 1-7.

49. VAISMAN, E. A ideologia e sua determinação ontológica. Revista Ensaio, São Paulo, Ensaio, n, 17/18, 1989, pp. 41-64.

50. VITTE, A. C. O desenvolvimento do conceito de paisagem e a sua inserção na geografia física. Revista Mercator, Fortaleza, v. 6, n. 11, pp. 71-78, 2007.

Artigo recebido em 03 de março de 2016.

Artigo aceito em 28 de julho de 2016. 